\title{
A STUDY OF BLEACHING OF THE FUNDUS OCULI IN PIGMENTARY DEGENERATIONS OF THE RETINA*
}

\author{
BY \\ J. GLOSTER AND D. P. GREAVES \\ Department of Experimental Ophthalmology, Institute of Ophthalmology, University of London
}

Fundus reflectometry has been in use for some years as a method of measuring the bleaching of visual pigments which occurs when light falls on the retina (Weale, 1953; Rushton, 1956). This principle has been extended to the study of changes in the intra-ocular vascular circulation, and an apparatus, designed for this purpose and giving a continuous recording of the amounts of light of three different colours reflected from the fundus oculi, has been described by Broadfoot, Gloster, and Greaves (1961). Certain modifications have been made in the apparatus (Buchanan, Gloster and Greaves, 1962) with a resultant increase in sensitivity, so that it is now possible to obtain a continuous record indicating bleaching in the fundus of the living human eye after exposure to light. The experiments to be described concern the changes in chromatic reflectivity of the fundus after exposure to light in eyes of healthy subjects, in enucleated ox eyes, and in eyes of patients with primary pigmentary degenerations of the retina and allied conditions.

\section{Methods}

A general description of the apparatus will be found in two earlier papers (Broadfoot and others, 1961; Buchanan and others, 1962). For the present study, certain modifications were needed for adequate fixation of the eye under examination and for its exposure to a bright light during the course of the recording. Fixation of the subject's head was obtained by biting on to a dental mould mounted on a brass plate, firmly secured to a table and placed at a convenient height. A cross-wire was mounted in the position shown in the diagram and adjusted so as to be in focus for the subject who was instructed to fix the point of intersection; some further adjustment of the cross-wire was necessary in the lateral direction so as to ensure that the area of fundus under test did not include the optic disc. A Lister operating lamp was mounted at right angles to the main optical axis of the ophthalmoscope. The light from the Lister lamp could be directed into the eye by a mirror held loosely in a frame placed at $45^{\circ}$ behind the objective lens of the ophthalmoscope (Figs 1 and 2, opposite).

The mirror was placed in its holder only during the actual period of bleaching so that the normal continuous record from the fundus was interrupted only for that period. A $12 \mathrm{v}$ $12 \mathrm{w}$ bulb was used in the Lister lamp, provision being made for coloured filters and an occluder to be interposed in the light beam.

The subject's pupil was dilated with homatropine and cocaine, fixation of the head and eye being obtained as already described. In some cases burnt cork was applied to the skin of the upper eyelid in order to reduce large excursions of the tracing which otherwise accompanied blinking. After the ophthalmoscope had been aligned various adjustments were made in order to obtain a satisfactory record. These included regulation of the

* Received for publication October 10, 1963. 
Fig. 1.-Diagram of apparatus as used during recording from fundus.
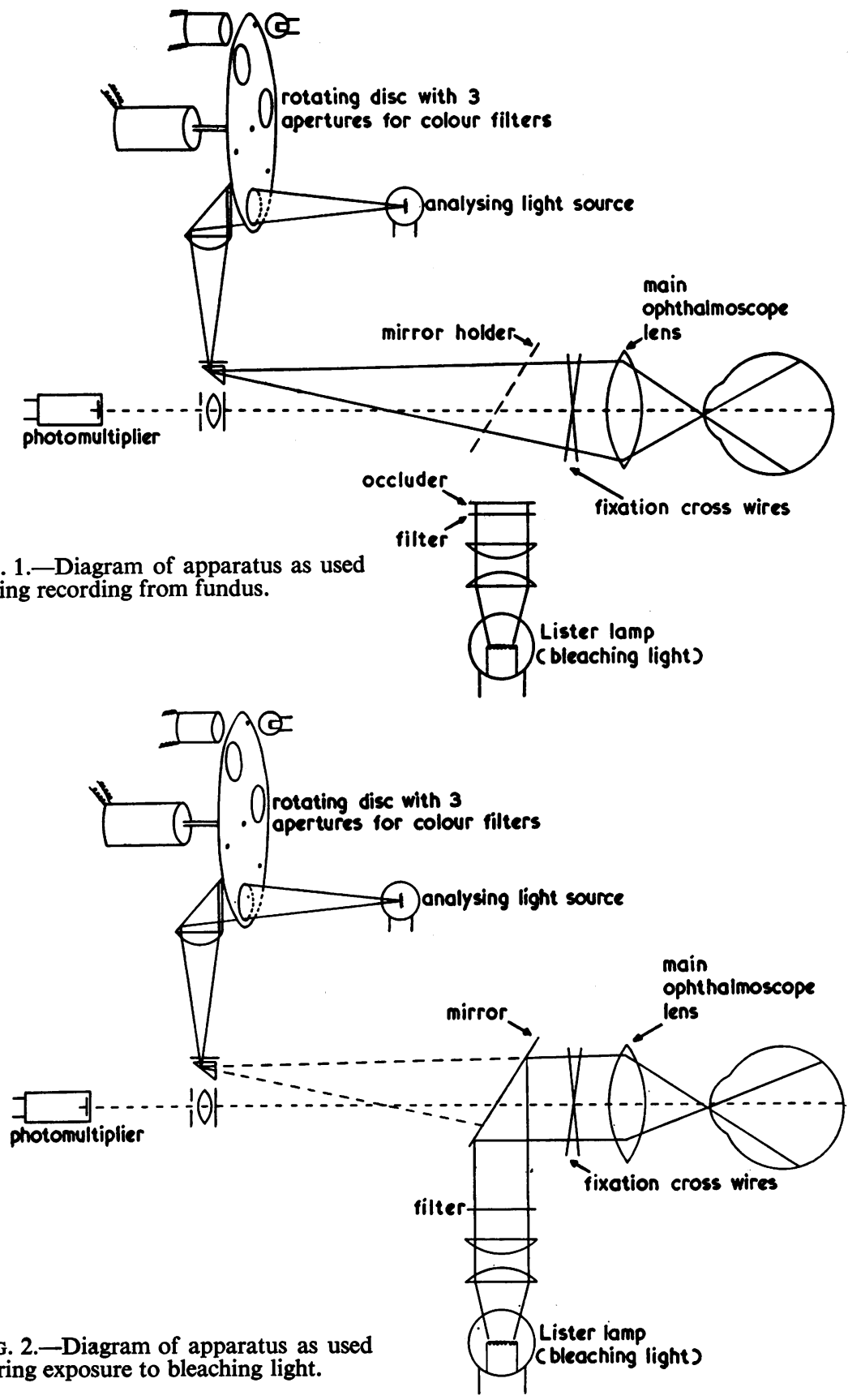

during exposure to bleaching light.

voltage supplied to the photomultiplier, selection of filters to be used in the rotating wheel, and adjustment of the recording apparatus. The time taken in doing this generally allowed the eye under test to reach a steady level of adaptation. No attempt was made to obtain full dark-adaptation, since the conditions of the experiment demand continuous exposure 
to light from the ophthalmoscope. The actual recording was then started and was continued until it was judged that the amount of light reaching the photomultiplier from the fundus had become steady, thus giving adequate base-lines from which subsequent measurements could be made. The eye was then exposed to the bleaching light by interposing the mirror in its frame and at the same time removing the occluder from in front of the Lister lamp. At the end of the period of bleaching the occluder was replaced simultaneously with removal of the mirror so that recording could continue immediately. Throughout the course of the experiments certain modifications were made in this general procedure. The colour of the bleaching light was varied; in a few of the earlier experiments "white" light was used, but in later tests colour filters were placed in front of the Lister lamp and, finally, in the standard experiment, a green filter (Ilford 624) was used. Furthermore, the duration of exposure to the bleaching light varied between $15 \mathrm{sec}$. and $2 \mathrm{~min}$., but in the standard experiment a 1-minute exposure was used.

To follow the changes which occurred after bleaching one of two procedures was adopted. Either the subject remained in position for several minutes thus giving a continuous record, or after recording the initial period following bleaching an interrupted tracing was obtained, allowing the subject to rest away from the ophthalmoscope for short periods between which he resumed his original position in front of the ophthalmoscope. At the end of the experiment the oscillator incorporated in the apparatus was used to mark on the tracing a series of deflections corresponding to known outputs from the photomultiplier. Changes in these outputs could be converted into changes in the amounts of light reaching the photomultiplier by the use of calibration data. The latter had been obtained by determining the changes in output of the photomultiplier corresponding to a series of known changes in amounts of light, produced by application of the inverse square law and expressed in arbitrary units. It was possible, therefore, from measurements made of the tracing, to deduce the relative changes in the amounts of light reflected from the fundus immediately after exposure to the bleaching light, and at intervals thereafter in those experiments in which further recording was obtained by the "continuous" or the "interrupted" techniques described above. Furthermore, by use of the calibration data, these alterations could be expressed as changes in optical density in the tissues reflecting light from the fundus oculi. Bleaching of the fundus after exposure to light was measured in ten healthy subjects whose ages ranged from 21 to 55 years. All except two had normal eyes; one subject had a congenital coloboma of the optic disc and in another the eye tested was amblyopic. Seven of these healthy subjects were males. Similar measurements were made on fifteen eyes of eight patients with primary pigmentary degeneration of the retina or an allied condition. The tracing from one eye of one patient was discarded because it was considered too irregular for any valid measurement to be made. The clinical condition of each patient is summarized in Table I (opposite). The tests were carried out over a period of 7 months, those conducted on the healthy subjects alternating with those on patients.

Three experiments were carried out on ox eyes which had been enucleated about one minute after the death of the animal. They were placed immediately in ice-cold KrebsRinger solution and brought back to the laboratory. The ophthalmic artery was dissected out and cannulated so that the whole vascular bed of the eye could be perfused continuously with oxygenated Krebs-Ringer solution buffered to $\mathrm{pH} 7 \cdot 3$. As soon as the perfusion was begun, the ox eye was immersed in a beaker of saline at $37^{\circ} \mathrm{C}$., apart from the cornea which was directed upwards. The eye was fixed in a steady position in the beaker by means of sutures passing from the perilimbal region to a surrounding metal ring. Perfusion was adjusted to a suitable rate, the usual pressure required being $60-100 \mathrm{~mm}$. $\mathrm{Hg}$. In order to adapt the apparatus for recording from an eye with an optical axis directed vertically instead of horizontally, a plane mirror was placed at an angle of $45^{\circ}$ beyond the objective 
TABLE I

PARTICULARS OF EIGHT PATIENTS WITH RETINAL DISEASE

\begin{tabular}{|c|c|c|c|c|}
\hline Patient No. & $\begin{array}{l}\text { Age } \\
\text { (yrs) }\end{array}$ & Sex & Clinical Condition & Remarks \\
\hline 1 & 48 & $\mathbf{F}$ & Typical retinitis pigmentosa. & \\
\hline $\begin{array}{l}2 \\
3\end{array}$ & $\begin{array}{l}23 \\
29\end{array}$ & $\begin{array}{l}F \\
F\end{array}$ & $\begin{array}{l}\text { Typical retinitis pigmentosa } \\
\text { Retinitis pigmentosa sine } \\
\text { pigmento }\end{array}$ & Daughter of Patient 1 \\
\hline $\begin{array}{l}4 \\
5\end{array}$ & $\begin{array}{l}27 \\
28\end{array}$ & $\begin{array}{l}\mathbf{F} \\
\mathbf{M}\end{array}$ & $\begin{array}{l}\text { Typical retinitis pigmentosa } \\
\text { Typical retinitis pigmentosa }\end{array}$ & $\begin{array}{l}\text { Small post-subcapsular lens } \\
\text { opacities }\end{array}$ \\
\hline 6 & 29 & $\mathbf{M}$ & Typical retinitis pigmentosa & $\begin{array}{l}\text { Punctate post-subcapsular } \\
\text { opacities } \\
\text { Myope }\end{array}$ \\
\hline 7 & 51 & $\mathrm{~F}$ & $\begin{array}{l}\text { Atypical retinitis pigmentosa } \\
\text { (Minimal pigment change) }\end{array}$ & $\begin{array}{l}\text { Technically unsatisfactory } \\
\text { tracing from one eye discarded }\end{array}$ \\
\hline 8 & 19 & $\mathbf{M}$ & Typical retinitis pigmentosa & $\begin{array}{l}\text { Clinically unaffected brother } \\
\text { (aged 16) also tested }\end{array}$ \\
\hline
\end{tabular}

In all these cases there was a history of night blindness and the fields of vision were markedly contracted

lens of the ophthalmoscope, and in such a position as to alter suitably the direction not only of the light used for colorimetric analysis of the fundus but also of the bleaching light from the Lister lamp. The experiments on ox eyes were carried out at the same low level of ambient illumination and following the same general procedure as for human eyes.

\section{Results}

\section{(A) Preliminary Experiments}

These were done in order to develop a suitable technique for studying colorimetric changes after exposure to light in the fundi of healthy subjects and of patients with primary retinal degeneration, and in order to elucidate as far as possible the reason for these changes.

Fig. 3 (overleaf) shows the tracing from a healthy subject. A white bleaching light was used for approximately $80 \mathrm{sec}$., the analysing filters in the rotating wheel of the ophthalmoscope being Ilford Spectrum Red 608, Ilford Bright Spectrum Blue Green 623, and Ilford Bright Spectrum Yellow Green 625. It can be seen that, immediately after bleaching, the meter reading for red light showed only a slight fall, whereas the readings for the other two colours showed considerable rises. From the calibration data these effects were interpreted as indicating a small decrease in the amount of red light reflected from the fundus and a considerable increase in both blue-green and yellow-green light. This increase in the two latter was not sustained, there being a subsequent return approximately to the original levels after about $5 \mathrm{~min}$.

Fig. 4 (overleaf) shows the results of another experiment on the same subject. This time the analysing filters were red and yellow-green as before, with an Ilford Bright Spectrum Violet 621 substituted for the blue-green filter; also, instead of white, a green light was used for bleaching (Ilford Bright Spectrum Green 624) for a period of $60 \mathrm{sec}$. The changes for red and yellow-green are very similar to those in the previous experiment whereas that for violet was a comparatively small increase. The return of yellow-green to its original level after about 8 minutes is clearly seen. 


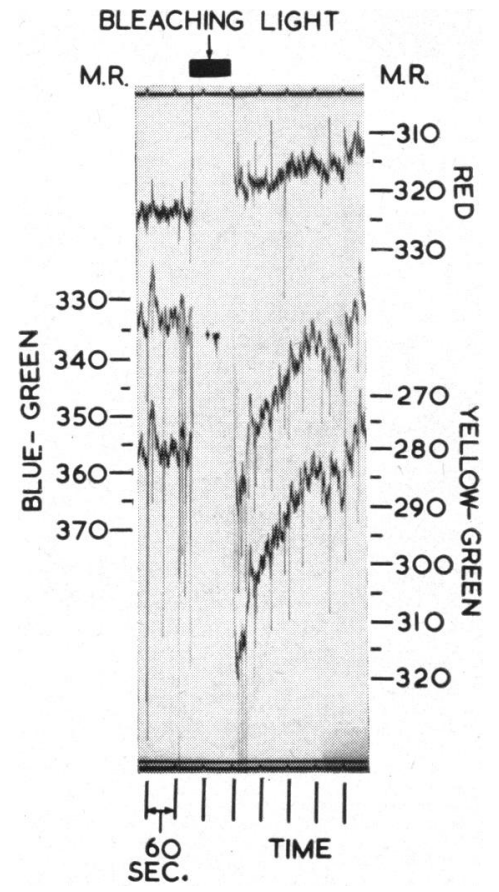

FIG. 3.-Effect of white bleaching light in a healthy subject.

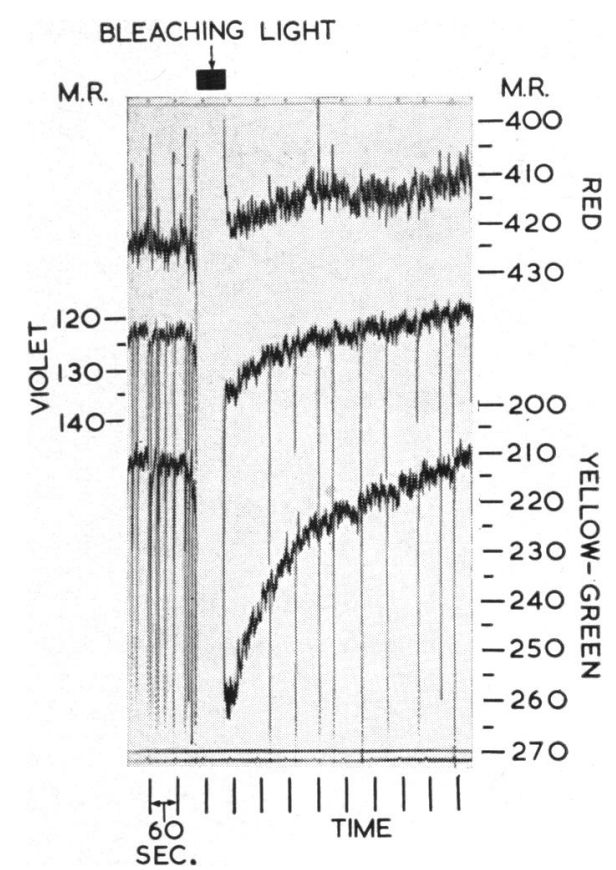

FIG. 4.-Effect of green bleaching light in a healthy subject. In this and subsequent tracings "M.R." = meter readings.

Figs 5 and 6 from two other subjects show essentially the sameeffects, but the changes after bleaching were recorded by the interrupted method described above. Neither of the subjects showed any significant changes in the level of red.
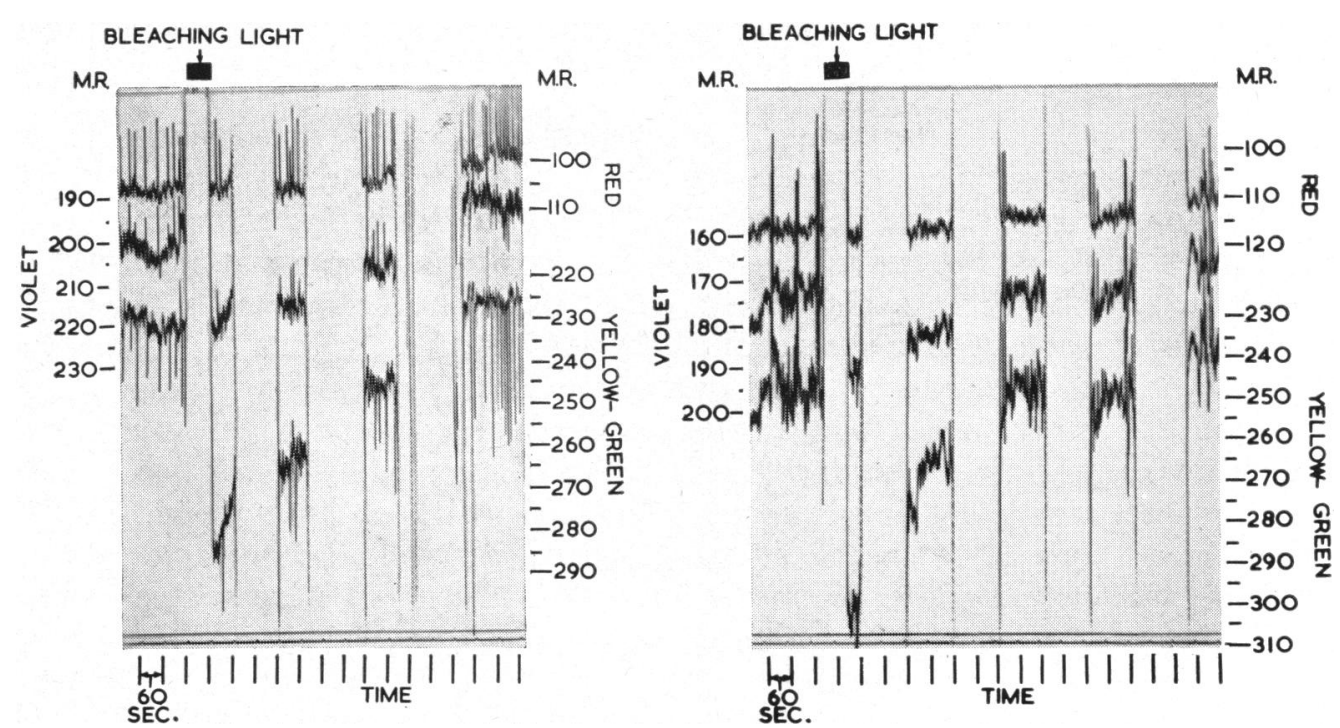

Figs 5 and 6.-Effects of green bleaching light in a healthy subject; "interrupted method".

Fig. 7 (opposite) shows the effect of varying the colour of the bleaching light upon the magnitude of the responses. In this experiment, the eye was exposed 
successively to lights of seven different colours for periods of $30 \mathrm{sec}$; interference filters were interposed in the path of the light from the Lister lamp. The wavelengths of maximum transmission of the filters (in $\mathrm{m} \mu$ ) were $447 \mathrm{~m} \mu, 469$ $\mathrm{m} \mu, 487 \mathrm{~m} \mu, 505 \mathrm{~m} \mu, 526 \mathrm{~m} \mu$, $549 \mathrm{~m} \mu$, and $586 \mathrm{~m} \mu$ respectively. The analysing filters were Spectrum Red (Ilford 608), Bright Spectrum Violet (Ilford 621), and Bright Spectrum Yellow-Green (Ilford 625). After the usual period of adaptation and when a sufficiently steady recording had been obtained, the eye was exposed to the coloured light and the amount of bleaching was recorded. A period of adaptation to the ambient illumination then followed, the duration of this varying from 10 to 20 minutes according to the magnitude of the bleaching effect obtained. Recovery from

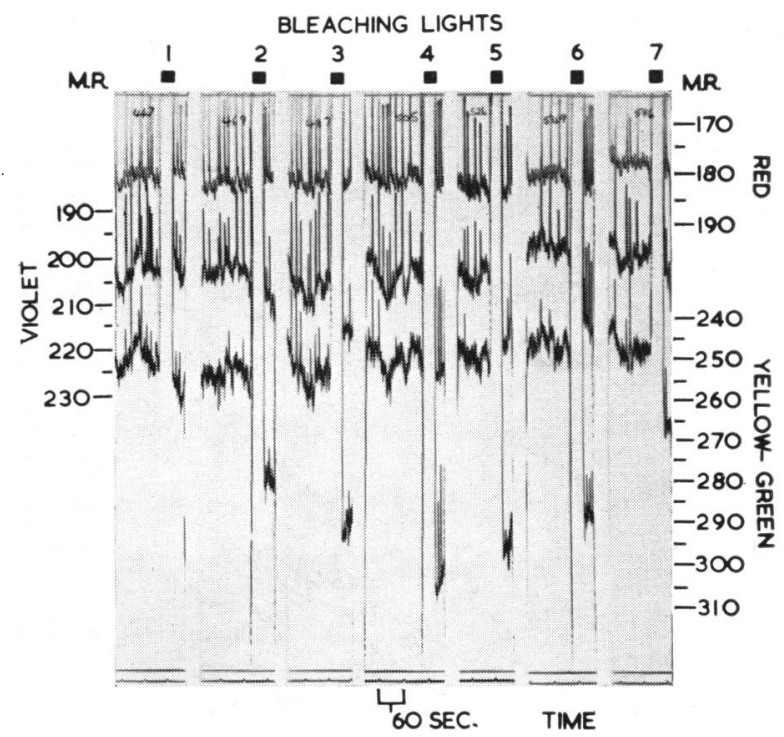

FIG. 7.-Variation in magnitude of the response to bleaching with lights of different wavelength, 1 to 7 being 447, 469, $487,505,526,549$ and $586 \mathrm{~m} \mu$ respectively. the latter was judged to be complete when the outputs on the recording had returned to their original levels. After recording these again for a short time the eye was exposed to a bleaching light of another colour and the response recorded. In this way, the effects produced with all seven interference filters were studied in turn. Fig. 7

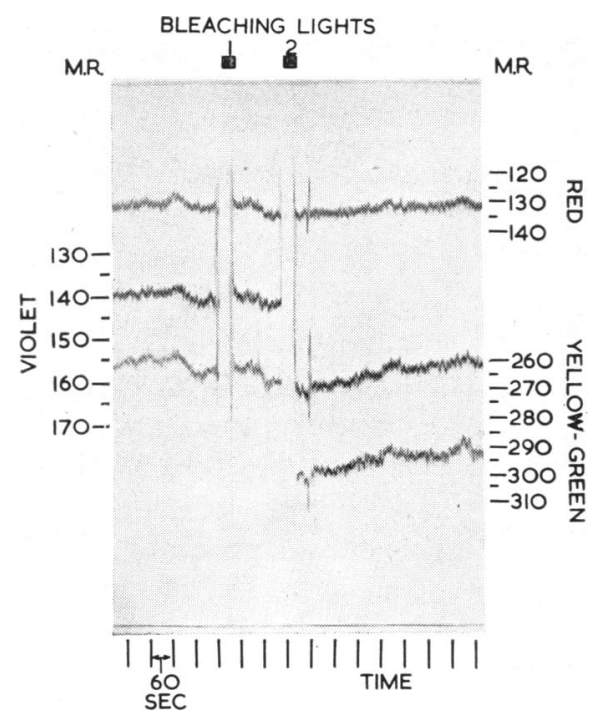

FIG. 8.-Effect of bleaching on a perfused ox eye. $1=$ red light; $2=$ green light. shows clearly that the largest effect was obtained with a green bleaching light $(\lambda$ $\max =505$ ) whilst progressively smaller effects resulted from the use of colours of wavelengths above and below this.

Fig. 8 illustrates an experiment on a perfused ox eye. The eye was first exposed to a red light, using an Ilford Spectrum Deep Red 609 filter in front of the Lister lamp. This produced no change in the amounts of red, violet, and yellow-green lights reflected from the fundus. After 2 to $3 \mathrm{~min}$., the eye was exposed to green light (interference filter with $\lambda \max =505 \mathrm{~m} \mu$ ). This produced no change in the amount of red light reflected from the fundus of the ox eye, but there were increases in both violet and yellow-green.

The results of a similar experiment on a second ox eye are given in Fig. 9 (overleaf). 
The first bleaching light was green (interference filter $\lambda \max =505 \mathrm{~m} \mu$ ). This caused no change in red, but there were increases in the amounts of violet and yellow-green reflected from the fundus; it can also be seen that the two latter began to return to-

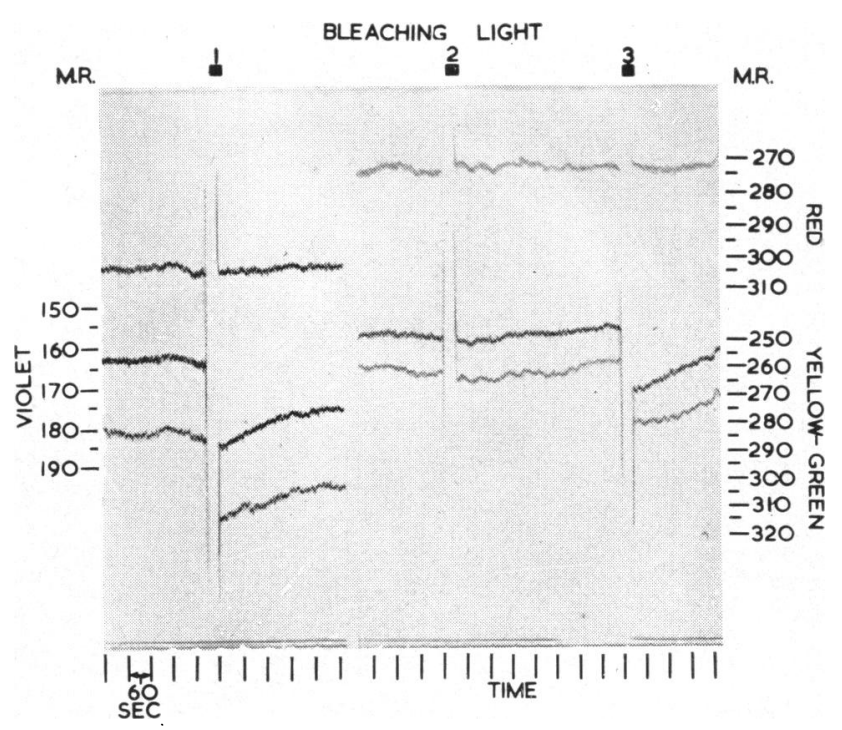
wards their initial levels immediately after bleaching. $25 \mathrm{~min}$. later, the eye was exposed to a red light (Ilford Spectrum Red 608) but this had no effect. Finally, about $33 \mathrm{~min}$. after exposure to the first bleaching light, the green light was used again; the result was similar to the first response although the changes for violet and yellow-green were less.

FIG. 9.--Effects obtained in a perfused ox eye, using green, red, and green light for bleaching successively.

\section{(B) Standard Experiments}

From experiences with the preliminary experiments, it was decided to adopt the following procedure in the standard experiments carried out on normal subjects and patients. The analysing lights were red, violet, and yellow-green, the filters in the rotating wheel being Ilford Spectrum Red 608, Bright Spectrum Violet 621, and Bright Spectrum Yellow-Green 625. The bleaching light was green, an Ilford Bright Spectrum Green filter 624 being placed in front of the Lister lamp. After a steady recording had been obtained, the eye under examination was exposed to the bleaching light for a period of $60 \mathrm{sec}$. When possible, the course of events after bleaching was followed by the "interrupted" method.

Results obtained in the standard experiment on normal subjects are shown in Figs 5 and 6. All ten subjects consistently showed a similar degree of "bleaching" of the fundus.

When the experiment was conducted on patients known to be suffering from retinitis pigmentosa, it was found that the quality of the tracings was below those obtained on healthy subjects, and it was thought that inexperience with the apparatus and possible difficulty in fixation were responsible for this. For example, it was not at all easy to maintain accurate fixation of the head if the patient had false teeth.

Figs 10,11, and 12 (opposite) show records from three different patients with primary degeneration of the retina. Despite the irregularities in the general form of the tracings it is quite clear that they show no effects comparable with the "bleaching" of healthy subjects.

From the tracings obtained in the standard experiments, it was possible to calculate the change in optical density of the fundus after exposure to light. As already mentioned, calibration data were available by means of which the electrical outputs 
FIG. 10.
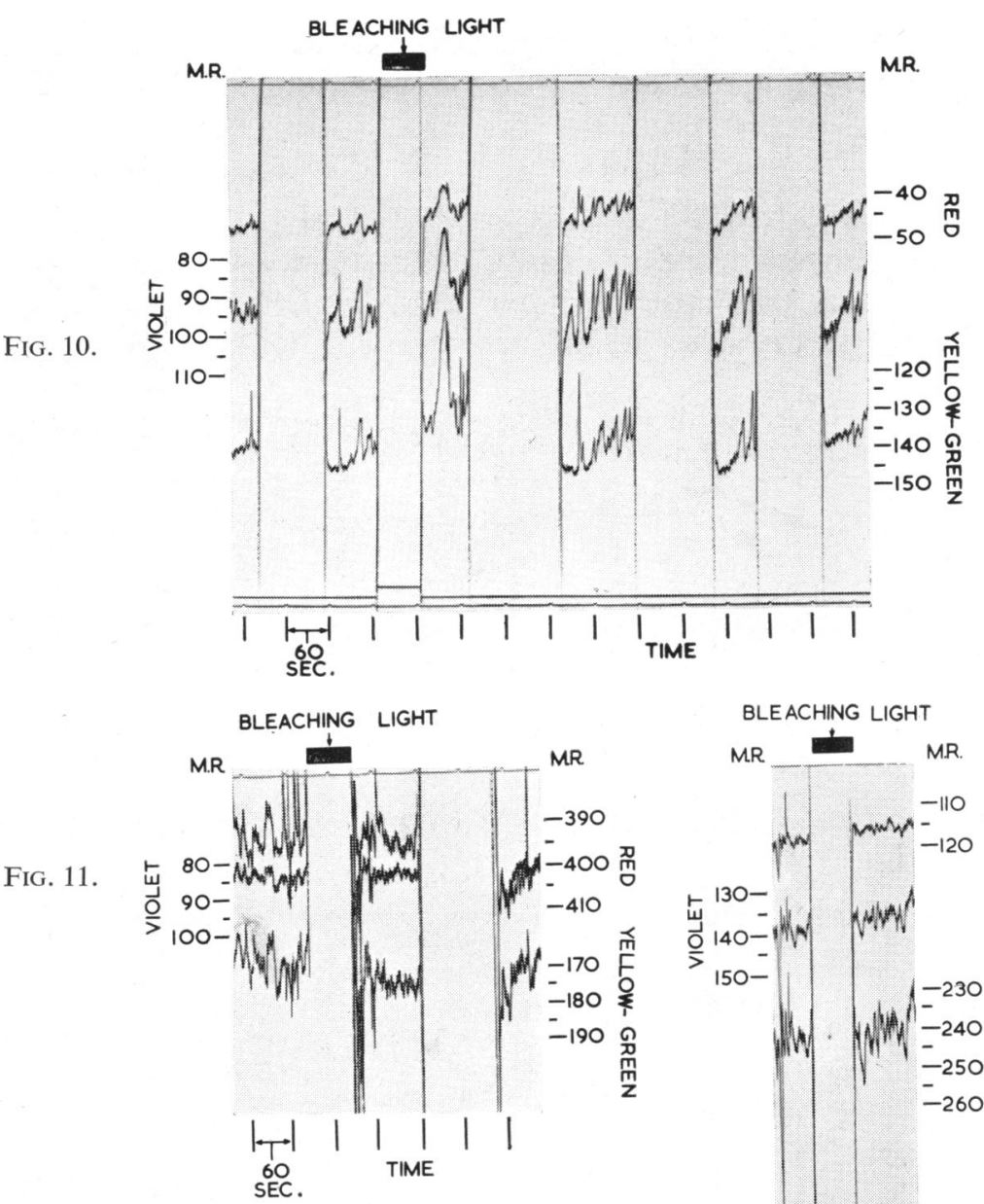

Figs 10, 11, 12.-Effect of bleaching in three patients with primary pigmentary degeneration of the retina.

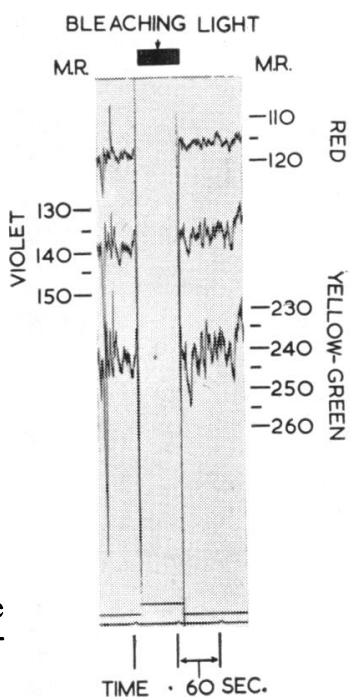

FIG. 12.

from the apparatus could be converted into amounts of light (expressed in arbitrary units) reflected by the fundus on to the photomultiplier.

The optical density, $D_{o}$, of the fundus before exposure to the bleaching light is given by the equation:

$$
D_{o}=\log \frac{L}{L_{o}}
$$

where $L$ is the amount of light incident upon the fundus and $L_{o}$ is the amount of light reflected by the fundus to the photomultiplier. After bleaching, the reflected light rises to a higher level $L_{b}$, the optical density, $D_{b}$, after bleaching being given thus:

$$
D_{b}=\log \frac{L}{L_{b}}
$$

The value of $L$ is indeterminable since it is the amount of light incident only upon that area of the fundus which reflects light on to the photomultiplier, but it may be 
regarded as constant throughout the experiment. The change in optical density $\Delta D$ resulting from bleaching the fundus is therefore given thus:

$$
\begin{aligned}
\Delta D= & D_{b}-D_{o}=\log \frac{L}{L_{b}}-\log \frac{L}{L_{o}} \\
& =\left(\log L-\log L_{b}\right)-\left(\log L-\log L_{o}\right)=\log L_{o}-\log L_{b}
\end{aligned}
$$

Table II gives the changes in optical density of the fundus for red, violet, and yellow-green light for the standard experiments on healthy subjects, and the comparable results for the patients with primary retinal degenerations are shown in Table III.

TABLE II

CHANGES IN OPTICAL DENSITY OF THE FUNDUS AFTER EXPOSURE TO LIGHT IN HEALTHY SUBJECTS

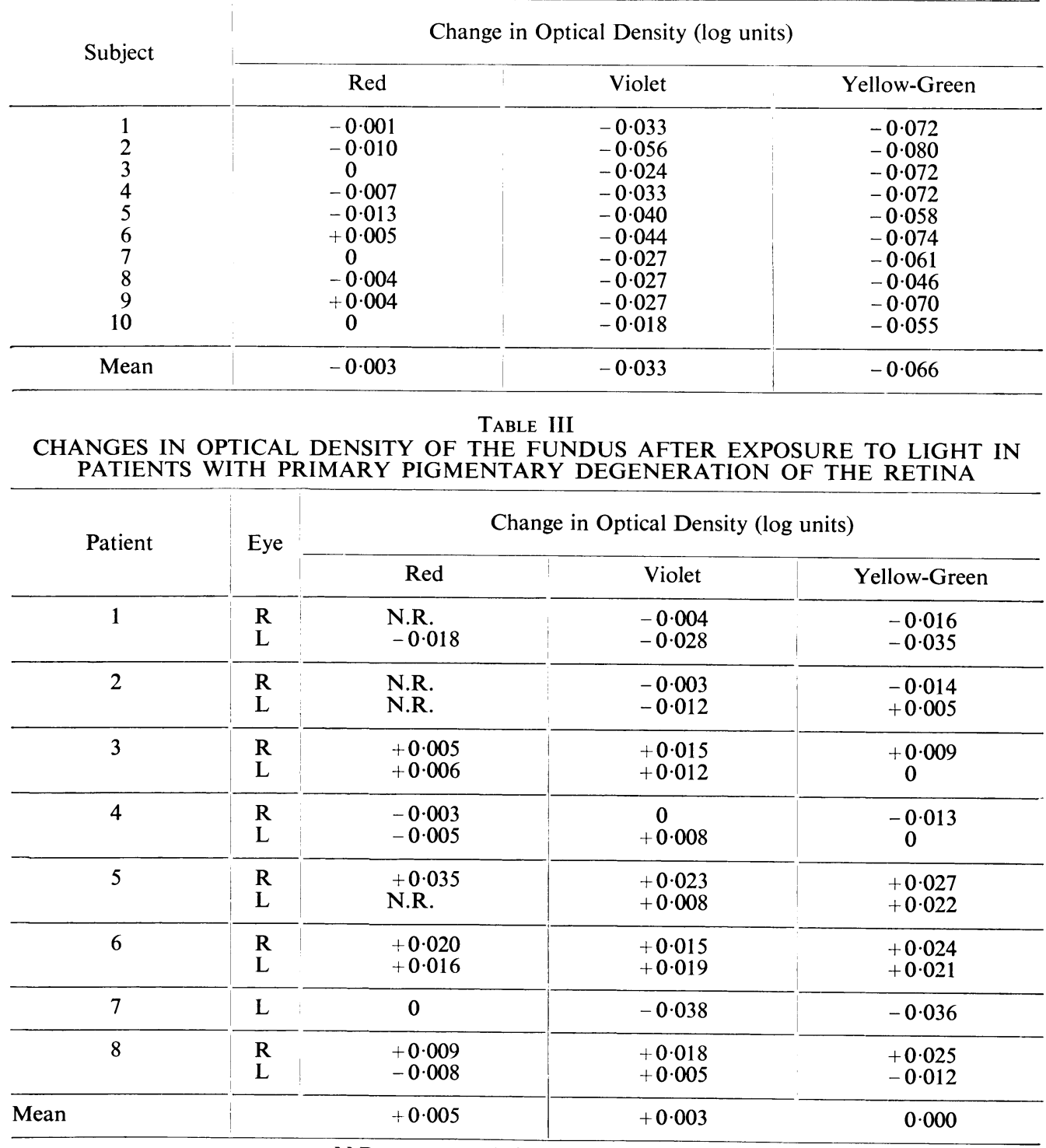

N.R. = no record, for technical reasons. 
A statistical analysis of the difference between the two groups in the mean changes in optical density for the three colours is presented in Table IV. From this it is clear that there was no significant difference between the groups in the effect of the bleaching light on the amount of red light reflected by the fundus, but the differences for the two other colours were highly significant.

TABLE IV

STATISTICAL ANALYSIS OF RESULTS PRESENTED IN TABLES II AND III

\begin{tabular}{|c|c|c|c|c|c|c|}
\hline Mean & & Red & \multicolumn{2}{|c|}{ Violet } & \multicolumn{2}{|c|}{ Yellow-Green } \\
\hline Healthy eyes & -0.003 & $t=1 \cdot 74$ & -0.033 & $t=5.67$ & -0.066 & $t=9 \cdot 20$ \\
\hline $\begin{array}{l}\text { Patients with primary pigmentary } \\
\text { retinal degeneration }\end{array}$ & +0.005 & $0.1>P>0.05$ & +0.003 & $P<0.01$ & 0.000 & $P<0.01$ \\
\hline
\end{tabular}

Fig. 13 is a histogram which compares the changes in optical density for yellowgreen light in the healthy subjects with those found in patients with primary pigmentary degenerations of the retina.

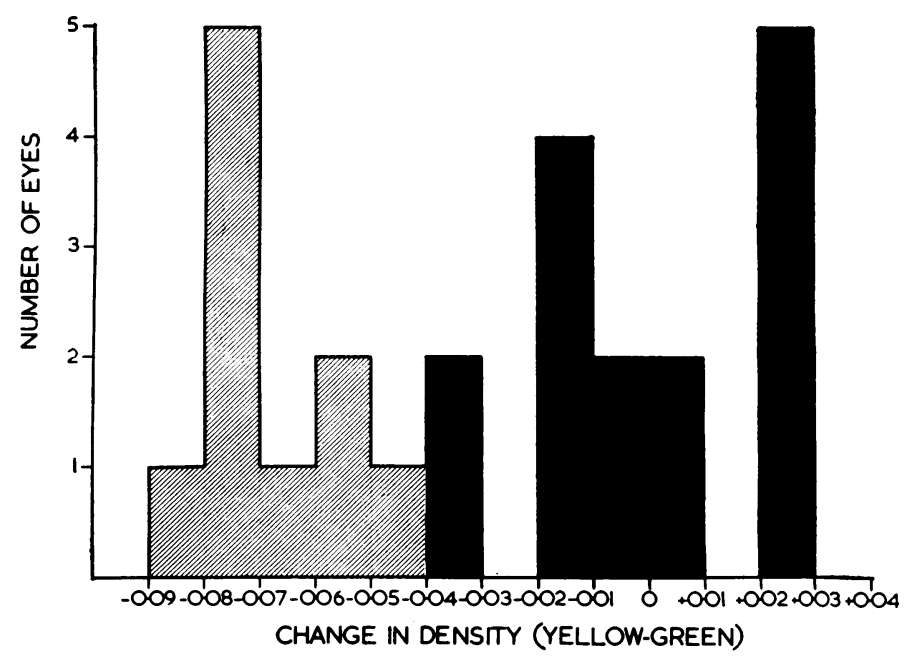

FIG. 13.-Summary of results in Tables II and III, indicating changes in optical density of the fundus (for yellow-green) after bleaching.

Shading Healthy eyes.

Black Eyes of patients with retinitis pigmentosa.

The apparently unaffected brother of one patient with retinitis pigmentosa was also tested. He gave results falling well within the normal range (Table V).

TABLE V

CHANGES IN OPTICAL DENSITY OF THE FUNDUS AFTER EXPOSURE TO LIGHT IN THE BROTHER OF PATIENT WITH RETINITIS PIGMENTOSA (PATIENT NO. 8)

Eye

Changes in Optical Density (log units)

\begin{tabular}{l|c|c|c} 
& Red & Violet & Yellow-Green \\
\hline Right & -0.003 & -0.018 & -0.074 \\
Left & +0.009 & -0.034 & -0.060 \\
\hline
\end{tabular}

Finally, Table VI (overleaf) gives results of repeated tests on one normal subject in order to give some idea of the consistency of the values obtained. 
TABLE VI

CHANGES IN OPTICAL DENSITY OF THE FUNDUS AFTER EXPOSURE TO LIGHT IN A HEALTHY SUBJECT ON FOUR OCCASIONS

\begin{tabular}{l|l|l|l}
\hline \multicolumn{1}{c|}{ Date } & Red & Violet & Yellow-Green \\
\hline 28.1 .63 & 0.000 & -0.024 & -0.072 \\
\hline 1.3 .63 & +0.001 & -0.028 & -0.070 \\
\hline 9.8 .63 & +0.002 & -0.023 & -0.050 \\
\hline 16.8 .63 & -0.003 & -0.019 & -0.068 \\
\hline
\end{tabular}

\section{Discussion}

The results given above demonstrate that, under the standard experimental conditions described, there are changes in the chromatic reflectivity of the fundus oculi in healthy human subjects after exposure to a bright green light. For convenience, we shall refer to these changes in reflectivity as "bleaching". Reflectivity to lights of all colours throughout the visible spectrum was not studied but, in the red, violet, and yellow-green ranges which were employed, the changes consisted always of increases in reflectivity to two out of the three colours, red showing no significant alteration; thus, the use of the term "bleaching" would seem to be justified. In all ten healthy eyes examined, bleaching was demonstrable immediately after exposure to the bright light, but was a transient phenomenon, as evidenced by the slow return to their initial levels of the amounts of violet and yellow-green light reflected.

Two explanations for the bleaching effect can be advanced. In previous experiments (Broadfoot and others, 1961) it was shown that procedures which reduced the amount of blood in the intra-ocular vascular bed caused increases in the amounts of violet and yellow-green light reflected by the fundus, with little alteration in the reflectivity for red light. On this basis, we could postulate that exposure to a bright light causes a transient vasoconstriction within the eye. The alternative explanation is that the changes recorded were due to the bleaching of a photo-sensitive pigment; it is, of course, well established that such an effect occurs in the human eye (Weale, 1953; Rushton, 1956), but it is necessary to consider whether the sensitivity of the apparatus used in the present study and the experimental conditions employed were compatible with this explanation.

A bleaching effect, similar to that recorded in human subjects, was also obtained in enucleated perfused ox eyes. In the latter, the possibility of intra-ocular vasoconstriction can be excluded since, during perfusion, the vascular bed of the ox eye was continuously filled with a colourless medium and it would seem that bleaching of a photo-sensitive pigment is the only explanation which can be given. The identity of the photo-sensitive pigment cannot be determined from the experimental results obtained, but it would appear reasonable to assume that it was visual purple.

In the healthy human eye, however, the supposition that the "bleaching" of the fundus recorded was in fact due to bleaching of visual purple rests upon three pieces of indirect evidence: 
(1) The rates at which the amounts of violet and yellow-green light returned to their initial levels after bleaching were compatible with the rate of regeneration of visual purple in vivo (Rushton, Campbell, Hagins, and Brindley, 1955).

(2) The variations in the degree of bleaching produced by exposure to lights of different colours do not contradict the hypothesis that the observed changes were attributable to bleaching of visual purple. Whilst our results show that maximum bleaching was obtained with a yellow-green light, as would be expected if visual purple were being bleached, the relative energy levels of the various coloured bleaching lights were not known precisely. To obtain satisfactory evidence along these lines would require a large series of experiments.

(3) As already pointed out, the results obtained in ox eyes were similar to those in human eyes, and it is clear that only the bleaching of a visual pigment can explain the findings in the former.

Although there is some uncertainty regarding the fundamental process underlying the bleaching effect, there is no doubt that the responses given by healthy eyes were different from those obtained in patients with primary pigmentary degenerations of the retina. In the latter the bleaching effect was either completely absent or diminished.

If we accept the explanation of the bleaching effect given above, these results suggest that, under our experimental conditions, bleaching of visual purple occurs only to a very limited extent after exposure to light in eyes affected by primary pigmentary degenerations of the retina.

Histological studies of such eyes show that degeneration of the sentient elements of the retina, in particular of the rods, is an early change in this condition, suggesting that the absence of bleaching is due to the loss of rods and the visual purple contained therein. There are, however, three other possibilities:

(1) That the rods are still intact but that they do not contain any visual purple.

(2) That the rods contain bleached visual purple which is, for some reason, incapable of regeneration from the bleached state or which can regenerate at a rate much less than that in the normal eye.

(3) That light is prevented from reaching visual purple in the retina affected by primary pigmentary degeneration. In this connexion it may be noted that the area of retina examined by the method described is approximately $8 \mathrm{~mm}$. in diameter with its centre at the fovea; it is therefore some distance from the equatorial region where the most marked pigmentary disturbances are seen with the ophthalmoscope.

Clearly, it is pointless to carry speculation further at this stage, although one may reasonably hope that the observations described may be extended so as to elucidate further the basic pathology of primary pigmentary degeneration and, perhaps, of other retinopathies. A profitable field of study would be provided by the relatives of known cases of retinitis pigmentosa; one such case reported here, the younger brother of a patient with retinitis pigmentosa, gave normal responses, but repeated examinations of such cases over a period of years might reveal a change in the 
bleaching response before any fundus changes were recognizable ophthalmoscopically. In addition, modifications in the apparatus and in the technique which would permit examination of areas of retina other than the macular region would be desirable. Amongst the other retinopathies, that due to chloroquine would seem to be particularly worthy of study.

Moreover, there can be little doubt that the value of measurements of the bleaching effect in elucidating the pathology of such conditions would be enhanced if they were supplemented by and correlated with the results of electroretinography and electro-oculography.

Perhaps the greatest merit of the technique is that it provides a completely objective measurement of one aspect of function in the eye affected by primary pigmentary degeneration, and in this way has advantages over other procedures, such as examination of the visual fields and determination of the range of dark adaptation. Evaluation of therapeutic measures in retinitis pigmentosa has always been difficult. It is hoped that the method described may be used for such a purpose; in particular, the response to long-term treatment with vitamin A preparations would seem particularly suitable for study.

\section{Summary}

(1) An apparatus originally designed for measuring changes in the choroidal circulation has been modified so that it records bleaching of the fundus of the living human eye after exposure to a bright light.

(2) The amounts of red, violet, and yellow-green lights reflected by the fundus of the living human eye were measured. The eye was then exposed to a bright light, various colours and times of exposure being used in the preliminary experiments. In healthy eyes the response consisted of an increased reflectivity of the fundus to violet and yellow-green lights, whilst that to red was unaltered. This response was termed "bleaching".

(3) Enucleated ox eyes were perfused with oxygenated Krebs-Ringer solution. After exposure to bright light, the fundi of these eyes showed changes in chromatic reflectivity similar to those in healthy human eyes.

(4) A standard experimental procedure was developed and was applied to eyes of healthy subjects and of patients with primary pigmentary degeneration of the retina and allied conditions.

(5) In ten eyes of healthy subjects, exposure to a bright light caused bleaching. In fifteen eyes of eight patients with pigmentary degeneration, bleaching was either absent or markedly less than that found in healthy eyes.

(6) It is suggested that the bleaching effect is due to the bleaching of visual purple.

(7) It is suggested that the absent or impaired bleaching observed in cases of primary pigmentary degeneration of the retina may be due to absence of visual purple or to its failure to regenerate.

(8) It is suggested that this technique may be of some value in elucidating the pathology of primary pigmentary degeneration of the retina or in providing an objective evaluation of therapeutic measures. 
We are grateful to Mr. W. A. Buchanan for his continued interest, help and advice with the electronic section of the apparatus, and to Mrs. S. Newberry for technical assistance. We should also like to thank Dr. Dorothy Campbell for referring two of her patients who have been included in our series.

\section{REFERENCES}

Broadfoot, K. D., Gloster, J., and Greaves, D. P. (1961). Brit. J. Ophthal., 45, 161.

Buchanan, W. M., Gloster, J., and Greaves, D. P. (1962). J. Physiol. (Lond.), 162, 2 P.

Rushton, W. A. H. (1956). Ibid., 134, 11.

Campbell, F. W., Hagins, W, A,, and Brindley, G. S. (1956). Optica Acta, 1, 183.

Weale, R. A. (1953). J. Physiol. (Lond.), 122, 322. 